\title{
Chapter 1 \\ Introduction: What Is Semiotics and Why \\ Is It Important for Mathematics \\ Education?
}

Over the last three decades, semiotics has gained the attention of researchers interested in furthering the understanding of processes involved in the learning and teaching of mathematics (see, e.g., Anderson et al. 2003; Sáenz-Ludlow and Presmeg 2006; Radford 2013a; Radford et al. 2008, 2011; Sáenz-Ludlow and Kadunz 2016). Semiotics has long been a topic of relevance in connection with language (e.g., Saussure 1959; Vygotsky 1997). But what is semiotics, and why is it significant for mathematics education?

Semiosis is "a term originally used by Charles S. Peirce to designate any sign action or sign process: in general, the activity of a sign" (Colapietro 1993, p. 178). A sign is "something that stands for something else" (p. 179); it is one segmentation of the material continuum in relation to another segmentation (Eco 1986). Semiotics, then, is "the study or doctrine of signs" (Colapietro 1993, p. 179). Sometimes designated "semeiotic" (e.g., by Peirce), semiotics is a general theory of signs or, as Eco (1988) suggests, a theory of how signs signify, that is, a theory of sign-ification.

The study of signs has long and rich history. However, as a self-conscious and distinct branch of inquiry, semiotics is a contemporary field originally flowing from two independent research traditions: those of C.S. Peirce, the American philosopher who originated pragmatism, and F. de Saussure, a Swiss linguist generally recognized as the founder of contemporary linguistics and the major inspiration for structuralism. In addition to these two research traditions, several others implicate semiotics either directly or implicitly: these include semiotic mediation (the "early" Vygotsky 1978), social semiotic (Halliday 1978), various theories of representation (Goldin and Janvier 1998; Vergnaud 1985; Font et al. 2013), relationships amongst sign systems (Duval 1995), and more recently, theories of embodiment that include gestures and the body as a mode of signification (Bautista and Roth 2012; de Freitas and Sinclair 2013; Radford 2009, 2014a; Roth 2010). Components of some of these theories are elaborated in what follows.

The significance of semiosis for mathematics education lies in the use of signs; this use is ubiquitous in every branch of mathematics. It could not be otherwise: the 
objects of mathematics are ideal, general in nature, and to represent them - to others and to oneself - and to work with them, it is necessary to employ sign vehicles, ${ }^{1}$ which are not the mathematical objects themselves but stand for them in some way. An elementary example is a drawing of a triangle - which is always a particular case-but which may be used to stand for triangles in general (Radford 2006a). As a text on the origin of (Euclidean) geometry suggests, the mathematical concepts are the result of the continuing refinement of physical objects Greek craftsmen were able to produce (Husserl 1939). For example, craftsmen were producing rolling things called in Greek kulindros (roller), which led to the mathematical notion of the cylinder, a limit object that does not bear any of the imperfections that a material object will have. Children's real problems are in moving from the material things they use in their mathematic classes to the mathematical things (Roth 2011). This principle of "seeing an A as a B" (Otte 2006; Wartofsky 1968) is by no means straightforward and directly affects the learning processes of mathematics at all levels (Presmeg 1992, 2006a; Radford 2002a). Thus semiotics, in several traditional frameworks, has the potential to serve as a powerful theoretical lens in investigating diverse topics in mathematics education research.

\subsection{The Role of Visualization in Semiosis}

The sign vehicles that are used in mathematics and its teaching and learning are often of a visual nature (Presmeg 1985, 2014). The significance of semiosis for mathematics education can also be seen in the growing interest of the use of images within cultural science. It was Thomas Mitchel's dictum that the linguistic turn is followed now by a "pictorial turn" or an "iconic turn" (Boehm 1994). The concentration on visualisation in cultural sciences is based on their interest in the field of visual arts and it is still increasing (Bachmann-Medick 2009). But more interesting for our view on visualisation are developments within science which have introduced very sophisticated methods for constructing new images. For example, medical imaging allows us to see what formerly was invisible. Other examples could be modern telescopes, which allow us to see nearly infinite distant objects, or microscopes, which bring the infinitely small to our eyes. With the help of these machines such tiny structures become visible and with this kind of visibility they became a part of the scientific debate. As long as these structures were not visible we could only speculate about them; now we can debate about them and about their existence. We can say that their ontological status has changed. In this regard images became a major factor within epistemology. Such new developments, which

\footnotetext{
${ }^{1}$ A note on terminology: The term "sign vehicle" is used here to designate the signifier, when the object is the signified. Peirce sometimes used the word "sign" to designate his whole triad, object [signified]-representamen [signifier]-interpretant; but sometimes Peirce used the word "sign" in designating the representamen only. To avoid confusion, "sign vehicle" is used for the representamen/signifier.
} 
can only be hinted at here, caused substantial endeavour within cultural science into investigating the use of images from many different perspectives (see, e.g., Mitchell 1987; Arnheim 1969; Hessler and Mersch 2009). The introduction to "Logik des Bildlichen" (Hessler and Mersch 2009), which we can translate as "The Logic of the Pictorial", focusses on the meaning of visual thinking. In this book, they formulate several relevant questions on visualisation which could/should be answered by a science of images. Among these questions we read: epistemology and images, the order of demonstrating or how to make thinking visible.

Let's take a further look at a few examples of relevant literature from cultural science concentrating on the "visual." In their book The culture of diagram (Bender and Marrinan 2010) the authors investigate the interplay between words, pictures, and formulas with the result that diagrams appear to be valuable tools to understand this interplay. They show in detail the role of diagrams as means to construct knowledge and interpret data and equations. The anthology The visual culture reader (Mirzoeff 2002) presents in its theory chapter "Plug-in theory," the work of several researchers well known for their texts on semiotics, including Jaques Lacan and Roland Barthes, with their respective texts "What is a picture?" (p. 126) and "Rhetoric of the image" (p. 135). Another relevant anthology, Visual communication and culture, images in action (Finn 2012) devotes the fourth chapter to questions which concentrate on maps, charts and diagrams. And again theoretical approaches from semiotics are used to interpret empirical data: In "Powell's point: Denial and deception at the UN," Finn makes extensive use of semiotic theories. Even in the theory of organizations, semiotics is used as means for structuring: In his book on Visual culture in organizations Styhre (2010) presents semiotics as one of his main theoretical formulations.

\subsection{Purpose of the Topical Survey on Semiotics in Mathematics Education}

Resonating with the importance of semiotics in the foregoing areas, the purpose of this Topical Survey is to explore the significance - for research and practice - of semiotics for understanding issues in the teaching and learning of mathematics at all levels. The structure of the next section is as follows. There are four broad overlapping subheadings:

(1) A summary of influential semiotic theories and applications;

(2) Further applications of semiotics in mathematics education;

(3) The significance of various types of signs in mathematics education;

(4) Other dimensions of semiotics in mathematics education.

Within each of these sections, perspectives and issues that have been the focus of research in mathematics education are presented, to give an introduction to what has already been accomplished in this field, and to open thought to the potential for 
further developments. This Survey is thus an introduction, which cannot be fully comprehensive, and interested readers are encouraged to read original papers cited, for greater depth and detail.

Open Access This chapter is distributed under the terms of the Creative Commons AttributionNonCommercial 4.0 International License (http://creativecommons.org/licenses/by-nc/4.0/), which permits any noncommercial use, duplication, adaptation, distribution and reproduction in any medium or format, as long as you give appropriate credit to the original author(s) and the source, a link is provided to the Creative Commons license and any changes made are indicated.

The images or other third party material in this chapter are included in the work's Creative Commons license, unless indicated otherwise in the credit line; if such material is not included in the work's Creative Commons license and the respective action is not permitted by statutory regulation, users will need to obtain permission from the license holder to duplicate, adapt, or reproduce the material. 